\title{
The Effect of PEG Tube Feeding Simulation on Nursing Students' Knowledge, Competence, Self-Reported Confidence and Satisfaction with Learning
}

\author{
By Hala Mohamed Mohamed Bayoumy* \\ Moradi A. Al Jadaani
}

\begin{abstract}
The study investigated the effect of PEG tube feeding simulation on nursing students' knowledge, competence, self-reported confidence and satisfaction with learning. A convenient sample of 37 nursing students was recruited from College of Nursing-Jeddah. Several tools were utilized for data collection, including: sociodemographic sheet, scenario-based knowledge test, 21-step checklist for performance evaluation, confidence self-assessment and students' satisfaction scales. A randomized controlled trial study design was used for current study. Students were randomly assigned to either a simulation or a video-led instruction group. Both groups had a 2-hour lecture of background information required for effectively performing PEG-tube feeding. Control group then watched a 25-minute video that covered the competency, while the experimental group had a lived simulation experience. Analysis of variace revealed a significant difference in knowledge between the two studied time points (pre/post- test) for participants in both study groups. However, no significant difference in neither knowledge nor competence acquisition was found between groups at any of studied time points. Both groups reported significantly high satisfaction and self-confidence scores at post-test. Results of current study indicated that psychomotor skill of PEG tube feeding is learned equally well with either lab simulation or a video-led instruction. This study examined outcomes immediately after the program and did not address knowledge and skill retention. Further research is needed to assess retention of studied outcomes over time.
\end{abstract}

Keywords: PEG tube feeding simulation, Satisfaction, Self-report confidence, Students' knowledge, Students' competence.

\section{Introduction}

Because of technology innovations, health care practice has witnessed a significant increase in the use of simulation as an educational tool for health care professionals and students (Liaw et al. 2012). Simulation is rapidly becoming an integral part of health professional education (Zhang et al. 2011). Simulation is a technique used to replace or amplify real-patient experiences with guided experiences and is artificially contrived to replicate substantial aspects of the real world in a fully interactive manner (Society for Simulation in Healthcare 2009). Simulation provides students with realistic clinical situations, and allows them to practice and learn in a safe environment (Arthur et al. 2012). Simulation can create a risk-free and error-tolerant environment similar to clinical settings, where students from different professions can learn

\footnotetext{
* Associate Professor, Cairo University, Egypt \& King Saud bin Abdul-Aziz University for Health Sciences, Ministry of National Guard-Health Affairs, Kingdom of Saudi Arabia.

$\dagger$ Teaching Assistant, King Saud bin Abdul-Aziz University for Health Sciences, Kingdom of Saudi Arabia.
} 
from and about each other to improve teamwork and quality of care (Zhang et al. 2011). As an educational strategy, simulation provides an immersive and experiential opportunity for learning (Aggarwal et al. 2010). It helps participants acquire insight into the complex relationships and interconnected structures within a particular context. It is intended to engage students in active learning, creative thinking and high level problem solving (Bland et al. 2011).

Simulation offers the opportunity for diverse styles of learning which are not offered in the classroom environment and which can result in an increase in confidence felt by the students (Jefferies and Rizzolo 2006). Lundberg (2008) emphasizes that providing students with the opportunity to repeat the simulation guided by feedback may increase confidence which is important, since low levels of confidence are usually recognised as a barrier to learning.

Hope et al. (2011) and Ross (2012) report that students show a positive response to simulation as a learning approach since it facilitates the application as and integration of knowledge from all three learning domains while they practice skills in a safe, controlled environment. Simulated learning can further offer particular benefits for improving humanistic abilities as well as the development of psychomotor, technical skills, overall confidence (Hope et al. 2011, Ross 2012, Tun and Kneebone 2011) and the application and understanding of nursing processes in different situations (Hunter and Ravert 2010).

Satisfaction is another important unit of measure in any learning process. A key issue in training nursing students is ensuring their satisfaction with planned learning experiences for developing the skills needed for effective patient care. Student's satisfaction is also a mandatory requisite to engaged and meaningful learning that could facilitate active and purposeful participation in simulation experiences (Prion 2008).

Although students voice satisfaction with human patient simulator experiences, the costs of faculty training, acquiring and maintaining manikins, should be weighed against costs and measurable learning outcomes (KardongEdgren et al. 2009). Harder (2009) added that although advances in technology and accessibility have led to widespread use of simulation, continued research as well as work in teaching and learning practices need to occur if we are to take advantage of these simulation experiences. Harder further claimed that simulation in nursing education is beginning to embrace the research opportunities available to determine whether simulation will enhance nursing education or be left in the corner to collect dust. On the same vein, Bland et al. (2011) emphasize that simulated learning deserves a critical evaluation to determine its effects and its full potential as a learning strategy. Research work should therefore focus on the impact of simulation on the nursing students' skills and knowledge development. Many previously published research studies have therefore focused on the use of simualtion on several aspects of nursing education; however there is still lack of quantitative research testing for the outcome of simulation on students' acquisition of advanced clinical skills, as well as their satisfaction and confidence after training. Specifically 
speaking, tube feeding and most importantly PEG "Percutaneous endoscopic gastrostomy" tube feeding skills has been given a little or no attention.

Percutaneous endoscopic gastrostomy (PEG) is a common procedure that provides enteral access for the administration of tube feeding in patients with functional GI tracts who are unable to ingest adequate amounts of food to meet their nutritional requirements (Galaski et al. 2009). Since the insertion of the percutaneous endoscopic gastrostomy tube is a minor surgical procedure that does not interfere with speech or swallowing, and is easy to follow-up and replace when blockage occurs, PEG has become a part of traditional care for a range of diagnoses (Martin et al. 2012) and a gold standard for long-term enteral feeding (Fonseca et al. 2013).

Although, PEG is commonly performed to avoid malnutrition and its related risks in patients with longstanding eating difficulties due to various pathological conditions that impair swallowing (Agha et al. 2011), it is not without adverse events. Moreover, despite its good safety record (Vanis et al. 2012), PEG can be associated with significant complications (Schrag et al. 2007). Aspiration is considered as one of the most frequently reported major complications of PEG which might also result in pneumonitis or pneumonia (Potack and Chokhavatia 2008).

The possible serious complications associated with such a procedure give the impetus for enhancing knowledge and skills through developing better training techniques to ensure the nursing students' competence in dealing with such a fundamental procedure and to minimize risks associated with "experimenting" on vulnerable patients. In addition, given decreased opportunities for skill practice and the mounting concerns for preparing graduate nurses who are competent in performing such important psychomotor skill, nurse educators are required to re-evaluate methods used to teach this skill (Ross 2012).

Despite available evidence supporting the efficacy of simulation technologies and the contribution these approaches can make to engage teaching and learning, educators need guidelines for effective implementation and curriculum integration (Arthur et al. 2012). It is also worth mentioning, that there have been no prior studies to address effectiveness of simulation use in the training of PEG among undergraduate nursing students. The strength of the debate and the importance of the issue emphasises the need for research to explore simulation as a teaching method to enhance students' abilities specially in this area.

Moreover, Tiffen et al. (2009) emphasize that although many schools utilize multiple methods for teaching a topic, little to no research has been done to examine if there is one superior method or if a combination of methods is most appropriate. It would therefore be appropriate to compare simulation against traditional methods of teaching.

In light of previous illustrations, the current study aimed at investigating the effect of PEG tube feeding simulation on nursing students' knowledge, competence, self-reported confidence and satisfaction with learning in comparison with a video-led instruction. It is hoped that this study will provide 
valuable information that will aid healthcare educators and direct curriculum developers with the most efficient use of their resources.

\section{Methodology}

Aim

The aim of the current study was to investigate the effect of the PEG tube feeding simulation on nursing students' knowledge, competence, self-reported confidence and satisfaction with learning.

\section{Setting}

The study was conducted in the College of Nursing-Jeddah (CON-J); King Saud bin Abdulaziz University for Health Sciences (KSAU-HS). The university is affiliated with the Ministry of National Guard - Health Affairs, Kingdom of Saudi Arabia.

\section{Study Participants}

A convenient sample of thirty-seven undergraduate baccalaureate nursing students, who registered for the course in medical - surgical nursing (adult II) were recruited for the current study. Students were from both stream I (regular students who were graduates of secondary school education) and stream II (holders of a bachelor degree in science who were seeking a second degree in nursing) at levels 3 and 6 of their study, respectively.

\section{Study Design}

A Randomized Controlled Trial (RCT) study design was used in the current study. This design is a gold stanrdard in measuring if the proposed intervention was associated with changes within or difference between experimental and control groups (Wood and Haber 2009).

\section{Data Collection Instruments}

Data collection was carried out utilizing several instruments. A sociodemographic data sheet was developed to elicit data related to students (age, education program or stream). Knowledge was measured using a scenariobased MCQ exam. This was an instructor-built test which was developed to measure students' mastery of knowledge necessary for performing the PEG tube feeding procedure safely and effectively.

Competency acquisition was assessed on a 21-step checklist. This checklist tested students' competency in performing PEG tube feeding safely and effectively. Each criterion in the checklist was evaluated on a two-response 
scale of zero (not done) to one (done). This checklist was adopted from Kozier and Erb's Fundamentals of Nursing (Berman et al. 2008). Content validity was assured through a panel of 5 experts including four academic staff members with extensive experience in teaching medical-surgical adult and critical care nursing courses in addition to an experienced teaching assistant.

A self-assessment Confidence Scale was developed by the researchers for measuring confidence. It comprised of 8 -items, rated on a seven-level scale ranging from 1 (not confident) to 7 (highly confident). Psychometric testing of the confidence scale showed a high internal consistency of Cronbach's alpha of 0.94 which supported the reliability of the scale.

In addition, a 19-item Students' Satisfaction Survey Questionnaire, developed by Feingold et al. (2004), was used. It is a 4-point Likert scale, (ranging from strongly disagree to strongly agree), utilized to determine the extent to which participants agreed with each of the items. This instrument had three subscales namely: realism (3 items), transferability (3 items) and value (6 items). It also included seven additional items related to the patient simulation experience itself. Reliability for the overall student satisfaction questionnaire was 0.86 , while the subscales showed a coefficient alpha of 0.41 for realism, 0.78 for transferability and 0.69 for value (Abdo and Ravert 2006).

\section{Ethical Considerations}

Once ethical and administrative approval for conducting the study was granted from College of Nursing - Jeddah, undergraduate students who were enrolled in the medical-surgical nursing course were approached by the researchers. The research study was extensively explained to the participants. Consent forms were signed after being assured that participation was entirely voluntary and that declining participation would not affect their course grades. Participants were also informed that all their responses would be kept anonymous and confidential throughout the study and that the data would be presented in an aggregated format to secure their identity.

\section{Procedure}

Participants were randomly assigned to either an experimental or a control group. Both groups had a 2-hour lecture that covered relevant background information necessary for performing the PEG-tube feeding competency effectively and safely. The control group had an extensive discussion after watching a 25-minute video that covered the competency performance, while the experimental group had a similar discussion during the simulation experience. The laboratory simulation was constructed as an active event in which students were immersed into a realistic clinical environment. Both simulation and video-led instructions utilized scenario-based education.

Participants were encouraged to integrate and synthesize pre-requisite knowledge provided in the theoretical part of the study while applying appropriate interpersonal and psychomotor skills. Students were also required 
to think critically and practice decision making skills utilizing the systematic nursing process approach with its interrelated steps of assessment, diagnosis, planning, implementation and evaluation.

The participants of each group were then divided into subgroups of 4-5 students to practice hands-on feeding on laboratory manikins; under the supervision of two teaching assistants. Assessments of students' acquired competency in performing the PEG tube feeding, confidence in performing the competency as well as satisfaction with the learning experience was carried out after the completion of the learning experience. The assessment of the students' knowledge was performed twice; before the educational activity (pre-test) and immediately after the end of learning (post-test).

\section{Data Management}

Data management was conducted using SPSS version 18. Necessary descriptive (means, frequencies, percentages, etc) and inferential statistics (univariate and multivariate analyses, e.g., chi-square, t-test, MANOVA, etc.) were carried out to measure differences in the studied outcomes between the two groups at different time points (pre and post-test).

\section{Results}

The experimental group included 19 participants while the control group included 18 participants. The mean age was $24.7 \pm 3.07$ and $22.3 \pm 5.49$ years for both groups respectively. The majority of the participants in the simulation group were from stream II $(\mathrm{N}=12,63.2 \%)$ while the video group was equally drawn from both stream I and II (9 from each). Chi square testing was not significant for the group per education program $(\mathrm{p}=0.65)$.

The multivariate (MANOVA) analysis is carried out to explore how independent variables of the subject group influence some patterning of response on the dependent variables of knowledge. Multivariate analysis of pre- and posttest task-related knowledge showed significant differences for all study participants $(\mathrm{F}=5.24, \mathrm{p}<0.000)$ with no significant differences between the experimental and control groups $(\mathrm{F}=0.65, \mathrm{p}=0.53)$. Participants in both video and simulation groups showed significant improvements in post-test knowledge compared to their pre-test scores. These results were consistently supported in the univariate independent-test analysis, as shown in Table 1. 
Table 1. Univariate Analysis for Pre and Post-Test Knowledge among Study Groups

\begin{tabular}{|lc|c|c|c|}
\hline Group & Pre test & Post test & Paired t-test \\
\hline Simulation M (SD) & $18.68(5.97)$ & $23.95(5.16)$ & $2.58^{* *}$ \\
\hline Video & M (SD) & $17.78(7.32)$ & $25.83(5.49)$ & $4.24 * * *$ \\
\hline Independent t-test & 1.79 & 0.001 & \\
\hline
\end{tabular}

Note: $* * \mathrm{p}$-value significant at $<0.01 ; * * * \mathrm{p}$-value significant at $<0.001$.

Source: Authors' estimations.

Concerning PEG feeding competency, there was no significant difference in any of the performance criteria (Table 2). Participants from both simulation and video groups performed equally satisfactorily. However, overall performance was better and error rates were less among the simulation group but with no statistical significance.

Table 2. Chi-Square Testing for PEG Competency Testing among Simulation and Video Groups

\begin{tabular}{|c|c|c|c|c|c|c|}
\hline \multirow{2}{*}{ Task } & \multicolumn{2}{|c|}{$\begin{array}{l}\text { Simulation } \\
\text { Group }\end{array}$} & \multicolumn{2}{|c|}{$\begin{array}{l}\text { Control } \\
\text { Group }\end{array}$} & \multirow[t]{2}{*}{ Chi } & \multirow[t]{2}{*}{ p-value } \\
\hline & Done & Not Done & Done & Not Done & & \\
\hline 1. Identifies the patient & 19 & 0 & 18 & 0 & - & - \\
\hline 2. Explains the procedure & 19 & 0 & 18 & 0 & - & - \\
\hline 3. Assembles equipment & 19 & 0 & 17 & 1 & 1.09 & 0.486 \\
\hline 4. Washes hands & 17 & 2 & 17 & 1 & 0.31 & 0.521 \\
\hline 5. Dons gloves & 19 & 0 & 18 & 0 & - & - \\
\hline 6. Provides privacy & 19 & 0 & 16 & 0 & 2.23 & 0.230 \\
\hline $\begin{array}{l}\text { 7. Assists to comfortable } \\
\text { position }\end{array}$ & 19 & 0 & 15 & 3 & 3.45 & 0.105 \\
\hline $\begin{array}{l}\text { 8. Assessed peri-stomal skin } \\
\text { properly }\end{array}$ & 16 & 3 & 15 & 3 & 0.005 & 0.643 \\
\hline \multicolumn{7}{|l|}{ 9. Checks location and patency } \\
\hline - aspiration & 17 & 2 & 16 & 2 & 0.003 & 0.677 \\
\hline $\begin{array}{l}\text { - follow policy for residual } \\
\text { amount }\end{array}$ & 18 & 1 & 16 & 2 & 0.424 & 0.479 \\
\hline $\begin{array}{l}\text { - frequency of residue } \\
\text { checking }\end{array}$ & 17 & 2 & 14 & 4 & 0.93 & 0.303 \\
\hline $\begin{array}{l}\text { - allow the water to flow } \\
\text { into the tube }\end{array}$ & 18 & 1 & 17 & 1 & 0.002 & 0.743 \\
\hline 10. Holds barrel above ostomy & 17 & 2 & 17 & 1 & 0.31 & 0.521 \\
\hline 11. Slowly pours solution & 19 & 0 & 17 & 1 & 1.09 & 0.486 \\
\hline 12. Adds water as prescribed & 17 & 2 & 15 & 3 & 0.298 & 0.473 \\
\hline 13. Clamps or plugs tube & 19 & 0 & 17 & 1 & 1.085 & 0.486 \\
\hline 14. Positions patient in sitting & 18 & 1 & 15 & 3 & 1.25 & 0.281 \\
\hline 15. Documents & 19 & 0 & 17 & 1 & 1.09 & 0.486 \\
\hline
\end{tabular}

Source: Authors' estimations.

Regarding self-reported confidence, results shown in Table 3, revealed that both the experimental and control groups showed a similarly high level of 
confidence in their performance of PEG tube competency. Study participants' reports of confidence in providing PEG tube feeding after education were positive in both groups.

Table 3. Independent t-test For Confidence Measure among Both Study Groups

\begin{tabular}{|c|c|c|c|c|}
\hline Item & \begin{tabular}{|c|} 
Simulation \\
Group \\
M (SD) \\
\end{tabular} & $\begin{array}{c}\text { Video } \\
\text { Group } \\
\text { M (SD) } \\
\end{array}$ & t-test & p-value \\
\hline 1. Administers PEG tube & $5.53(1.2)$ & $5.33(1.5)$ & 43 & 0.674 \\
\hline $\begin{array}{l}\text { 2. Checks correctly the location and patency } \\
\text { of a tube }\end{array}$ & $5.32(1.4)$ & $5.78(1.6)$ & -0.92 & 0.363 \\
\hline 3. Intervenes in case of none patent tube & 5.53 & $5.06(1.7)$ & 0.61 & .343 \\
\hline due and is & $5.53(1.2)$ & $5.83(1.7)$ & 0.68 & 0.523 \\
\hline akage after rui & $5.58(1.2)$ & $5.94(1.4)$ & 0.81 & 0.400 \\
\hline 6. Assesses peri-stomal skin properly & 5.58 & $5.50(1.7)$ & 0.16 & 0.877 \\
\hline $\begin{array}{l}\text { 7. Applies the skin barrier } \& \text { appropriate } \\
\text { dressing }\end{array}$ & $5.37(1.8)$ & $5.39(1.5)$ & -0.04 & 0.970 \\
\hline $\begin{array}{l}\text { 8. Documents and report any abnormal } \\
\text { finding }\end{array}$ & 5.79 & $5.00(2.2)$ & 1.24 & 0.223 \\
\hline Total Confidence Score & $44.21(9.4)$ & $43.83(11.4)$ & 0.11 & 0.913 \\
\hline
\end{tabular}

Source: Authors' estimations.

Overall satisfaction with the learning experience for all study participants, from both groups, was positively reported $(61.3 \pm 7.3,60.1 \pm 11.4$; for simulation and video groups respectively). The overwhelming majority of participants rated their satisfaction with the education experience highly in all areas with no exception. The participants felt that simulation was realistic, valuable, improved their confidence and interaction, and reinforced their objectives.

Regarding satisfaction per group, satisfaction showed equal results between both study groups. There were no significant differences in any of the measures of satisfaction as shown in Table 4. 
Table 4. Independent t-test for Levels of Satisfaction among Both Study Groups

\begin{tabular}{|c|c|c|c|c|}
\hline Item & \begin{tabular}{|c|} 
Simulation \\
Group \\
M (SD) \\
\end{tabular} & $\begin{array}{c}\text { Video } \\
\text { Group } \\
\text { M (SD) }\end{array}$ & t-test & p-value \\
\hline 1. Scenario used recreates real-life situations $(\mathrm{R})$ & $3.0(0.47)$ & $3.3(0.75)$ & -1.35 & 0.184 \\
\hline 2. Scenario adequately tests technical skills (V) & $3.2(0.50)$ & $3.2(0.79)$ & -0.01 & 0.968 \\
\hline $\begin{array}{l}\text { 3. Scenario adequately tests clinical decision- } \\
\text { making }(\mathrm{V})\end{array}$ & $3.2(0.63)$ & $2.9(0.58)$ & 1.61 & 0.117 \\
\hline $\begin{array}{l}\text { 4. I was adequately prepared for the testing } \\
\text { experience (I) }\end{array}$ & $3.4(0.49)$ & $3.1(0.80)$ & 1.44 & 0.160 \\
\hline rientation to working with patient & $3.2(0.69)$ & $2.9(0.80)$ & 0.87 & 0.390 \\
\hline sembled a real setting $(\mathrm{R})$ & 310 & $2.9(0.81)$ & -0.80 & 0.428 \\
\hline 7. Tem & & $3.1(0.96)$ & 1.32 & .196 \\
\hline 8. Ligh & & $3.1(0.73)$ & 0.87 & 393 \\
\hline or provides a realistic patient & $2.9(0.99)$ & $3.1(0.83)$ & -0.72 & 0.479 \\
\hline cal skills taught are valuable (I) & 4) & 3.1 & -0.02 & .984 \\
\hline $\begin{array}{r}\text { 11. Clin } \\
\text { valu }\end{array}$ & 81) & $3.3(0.84)$ & -0.26 & 0.79 \\
\hline $\begin{array}{l}\text { confidence about going to the } \\
\text { T) }\end{array}$ & $3.6(0.59)$ & $3.2(0.88)$ & 1.67 & 0.105 \\
\hline $\begin{array}{l}\text { 13. Was a val } \\
\text { (V) }\end{array}$ & $3.3(0.56)$ & $3.3(0.75)$ & -0.07 & 0.947 \\
\hline $\begin{aligned} \text { 14. Int } \\
\text { col }\end{aligned}$ & $3.3(0.67)$ & $3.2(0.92)$ & 0.56 & 0.576 \\
\hline $\begin{array}{r}\text { 15. Wo } \\
\text { acti }\end{array}$ & $3.4(0.51)$ & $3.2(0.88)$ & 0.85 & 0.402 \\
\hline $\begin{array}{l}\text { 16. Pace reflected flow of actual clinical settin } \\
\text { (I) }\end{array}$ & $2.9(0.52)$ & $3.0(0.77)$ & -0.25 & 0.8 \\
\hline $\begin{array}{l}\text { 17. Prepared me to perform in the "real-life" } \\
\text { clinical setting (T) }\end{array}$ & $3.1(0.71)$ & $3.4(0.92)$ & -1.46 & 0.154 \\
\hline $\begin{array}{l}\text { 18. Received adequate feedback regarding my } \\
\text { performance (V) }\end{array}$ & $3.5(0.51)$ & $3.2(0.81)$ & 1.14 & 0.264 \\
\hline $\begin{array}{l}\text { 19. Overall, the experience enhanced my } \\
\text { learning }(\mathrm{V})\end{array}$ & $3.4(0.68)$ & $3.4(.85)$ & $\mid-0.08$ & 0.936 \\
\hline ction Score & $61.3(7.3)$ & 60.1 (11.4) & 0.37 & 0.715 \\
\hline $\mathbf{R e}$ & $3.2(0.69)$ & $2.9(0.54)$ & -1.17 & 0.251 \\
\hline & & $3.2(0.61)$ & 0.74 & 0.464 \\
\hline Transferability Score & $3.3(0.50)$ & $3.2(0.79)$ & 0.26 & 0.799 \\
\hline
\end{tabular}

Note: R: Realism; V: Value; T: Transferability; I: Additional items.

Source: Authors' estimations.

\section{Discussion}

The development and running of simulation programs is expensive and often faculty intensive. To justify simulation as an effective and appropriate teaching method, more data (Tiffen et al. 2009) that could provide empirical evidences in support of its application in clinical practice needs to be collected 
(Murray et al. 2008). Therefore, the current study investigated the effect of PEG tube feeding simulation on nursing students' knowledge, competence, self-reported confidence and satisfaction with learning.

The findings of the current study revealed significant improvements in the knowledge of study participants for the post-test compared to their pre-test scores but with no significant difference between the simulation and videocontrol group. This could be attributed to the fact that the education and learning materials were unified for both groups which might have resulted in an equal improvement in their knowledge after the educational experience. The current results were consistent with those shown in the study carried out by Morgan et al. (2002). Morgan et al. study showed that while there were significant educational gains achieved by all medical students in both simulation-assisted and the video-assisted education groups at post-test in the management of patients with myocardial infarction, there was no statistical significance between these groups as well.

Similarly, a previous research study by Kinney and Henderson (2008), comparing the impact of low-fidelity simulation as opposed to traditional lectures on learning medication administration among nursing students, indicated that utilizing a low-fidelity simulation technique yields immediately an improved score than lecture alone could account for. Ackermann (2009) indicated that the human patient simulation program had a positive effect on both acquisition of knowledge and skills among nursing students.

\section{Competency Acquisition}

Concerning PEG tube feeding competency, the study showed that participants from both study and control groups performed equally satisfactorily. There was no significant difference in the performance between the study groups, however overall performance was better and error rates were less among the simulation group. In concordance, the results from experimental studies by Blum et al. (2010) and Brannan et al. (2008) found no statistically significant differences in the mean scores of clinical competence among their studied groups. Another study by Chiu et al. (2009) further supports current findings. Chiu et al. (2009) had examined the effectiveness of two programs: an interactive computer assisted simulation instruction and an instructor-led video-tape learning program, to teach the correct use of the National Stroke Scale, among nurses. Scores of both groups significantly increased after intervention with an insignificant difference between their study groups at posttest.

Murray et al. (2008) contended that although simulation cannot replicate the clinical context, its use in the education and training of health service personnel, can mirror this approach by providing a non-threatening and safe environment. The authors added that this affords opportunities for learners to develop cognitive, psychomotor and affective competencies through trial and error experiences away from the patient's bedside. 


\section{Satisfaction and Self-Confidence}

Interestingly, the study findings with regards to students' satisfaction and self-confidence revealed consistently positive results. Levels of satisfaction and self-confidence were high among students engaged in both teaching strategies. Previous research has also produced similar results. Tiffen et al. (2009) study showed that a human patient simulation experience could improve confidence in health assessment skills for advanced practice nursing students following a simulation experience. Gore et al. (2011) found that following simulation, students experienced an increase in their confidence in performing patient care and a decrease in anxiety which together serve to create a meaningful learning experience.

Moreover, Abdo and Ravert (2006), in a study that measured students' satisfaction with simulation experiences, reported that participants felt the experiences recreated real-life situations, tested their clinical decision making, and prepared them for the "real-life" clinical practice. Abdo and Ravert, further, added that since simulation provide students with a variety of patient's problems, this could explain the reason why students felt that they had an opportunity to learn the appropriate care, a matter that could increase their confidence when in the clinical setting. Students' narratives and comments drawn from the current study similarly reflected their positive attitude to simulation activities. These included: "simulation experience was helpful", "it helped to understand and analyze the information", "I had the opportunity to learn and practice in a safe environment without the fear of risking a patient's life", "It was as close to reality as possible".

On the contrary, the study by Liaw et al. (2012) contended that there is a potential danger of overestimating self-confidence when evaluated in a simulation-based assessment. Liaw et al. therefore did not support the validity of the knowledge test and self-confidence measures observed in a simulationbased assessment as they might not be accurate indicators for future clinical performance.

It is also worth mentioning that evidence for support of effectiveness of video-led instruction is shown in the literature (Cardoso et al. 2012, Salina et al. 2012). Salina et al. (2012) evaluated the efficacy of a teaching video for moving an uncooperative patient as an instrument to reinforce nursing techniques. The Salina et al. study results demonstrated that video-use represents an important tool to refresh and reinforce learning where students who had seen the video were more successfully in applying the correct moving technique. Cardoso et al. (2012) also found that the use of video, for teaching puncture and heparinization of totally implantable central venous access ports, proved to be a strategy that increased both cognitive and technical knowledge and could be viable in the teaching-learning process. Similarly, Williams et al. (2009) found that nursing students perceived the pre-prepared videos positively in relation to learning potential, clinical relevance to practice, and information processing quality and also reported that simulations were educationally, professionally, and clinically relevant. 
Consequently, reasons for non-significant findings in the current study might be multifactorial. On one hand, the study was conducted on a small sample size of only 37 nursing students who registered for the medical-surgical nursing course during the study period, and on the other hand the fact that the study was conducted in only one setting could mountain another limitation. Moreover, the increasing evidence in the literature in favor of use of video as an effective teaching strategy (Cardoso et al. 2012, McConville and Lane 2006) could have constituted another plausible reason for the current findings.

Taken together, the overall study findings showed that simulation had positive impact on students' knowledge, competency acquisition, confidence as well as satisfaction with their learning experience; and that video-led instruction was also an effective alternative teaching methodology in PEG tube feeding education. To sum up, Jarzemsky (2012) emphasized that the nursing faculty now faces the challenge of efficiently combining teaching strategies to prepare nurses for contemporary practice, therefore, there is no question that simulation is a successful approach, but there is much to learn about best practices associated with its use in nursing education".

\section{Conclusion and Recommendations}

Finding clinical experiences that prepare undergraduate students to practice in an increasingly demanding workplace is a challenge for nurse educators giving that availability of clinical education sites has declined and increasing challenges of findings appropriate clinical teaching situations for students to master such critical skills as PEG tube feeding. Nurse educators must choose and employ creative teaching strategies based on research findings in order to prepare students for successful practice (National League for Nursing 2005). Therefore the current study was based on the need to explore best practices for teaching PEG tube feeding. The effect of PEG tube feeding simulation on nursing students' knowledge, competence, self-reported confidence and satisfaction with learning was investigated.

The current study findings showed that using simulation as an educational experience provided effective learning and successfully increased knowledge, competence, confidence and satisfaction among students. Video-led instructions provided similar positive results among the studied group. It is recommended that these two teaching methodologies should be considered in planning in-service education for nurses caring for patients receiving PEG tube feeding.

However, the small sample size and the fact that the study was carried out in only one setting were two main limitations of worth mentioning. Lastly, the fact that students were informed about the study and they were being examined might have heightened the attention levels and cognitive retention of the finer details that may have been different if they were unaware of being part of the study. This matter could not, unfortunately, be obscured from them for the ethical concerns. 
Future research should focus on measuring the retention of knowledge at a 3 and 6 months interval after such educational activities for further comparing effectiveness of both studied teaching methodologies. Finally, since the study subjects included only junior nursing students, it is recommended that other types of healthcare providers with more experiences -including nurses- could present good potentials for additional research.

\section{References}

Abdo A, Ravert P (2006) Student satisfaction with simulation experiences. Clinical Simulation in Nursing Education 2: e13-e16.

Ackermann AD (2009) Investigation of learning outcomes for the acquisition and retention of CPR knowledge and skills learned with the use of high-fidelity simulation. Clinical Simulation in Nursing 5(6): e213-e222.

Aggarwal R, Mytton OT, Derbrew M, Hananel D, Heydenburg M, Issenberg B, MacAulay C, Macini ME, Morimoto T, Soper N, Ziv A, Reznick R (2010) Training and simulation for patient safety. Quality and Safety in Health Care 19(Suppl 2): i34-i43.

Agha A, Al-Saudi D, Furnari M, Ali MMA, Al-Majadah SSA, Savarino V, Inferrera S, Giannini EG (2011) efficacy of 48-hour post-operative antibiotics prophylaxis for patients undergoing percutaneous endoscopic gastrostomy tube in preventing site infection. Journal of Gastrointestinal and Liver Diseases 20(2): 131-134.

Arthur C, Levett-Jones T, Kable A (2012) Quality indicators for the design and implementation of simulation experiences: A Delphi study. Nurse Education Today 1-5.

Berman A, Snyder S, Kozier B, Erb G (2008) Kozier \& Erb's Fundamentals of Nursing: Concepts, Process, and Practice ( ${ }^{\text {th }}$ Edn.). Pearson: Prentice Hall.

Bland AJ, Topping A, Wood B (2011) A concept analysis of simulation as a learning strategy in the education of undergraduate nursing students. Nurse Education Today 31: 664-670.

Blum CA, Borglund S, Parcells D (2010) High-fidelity nursing simulation: impact on student self-confidence and clinical competence. International Journal of Nursing Education Scholarship 7(1): 1-14.

Brannan JD, White A, Bezanson JL (2008) Simulator effects on cognitive skills and confidence levels. The Journal of Nursing Education 47(11): 495-500.

Cardoso AF, Moreli L, Braga FTMM, Vasques CI, Santos CB, Carvalho EC (2012) Effect of a video on developing skills in undergraduate nursing students for the management of totally implantable central venous access ports (TIAP). Nurse Education Today 32: 709-713.

Chiu Su-C, Cheng Kuei-Y, Sun Tzu-K, Chang Ku-C, Tan Teng-Y, Lin Tsu-K, Huang Yu-C, Chang Jui-K, Yeh Shu-H (2009) The effectiveness of interactive computer assisted instruction compared to videotaped instruction for teaching nurses to assess neurological function of stroke patients: a randomized controlled trial. International Journal of Nursing Studies 46: 1548-1556.

Feingold CE, Calaluce M, Kallen MA (2004) Computerized patient model and simulated clinical experiences: evaluation with baccalaureate nursing students. Journal of Nursing Education 43(4): 156-163. 
Fonseca J, Santos CA, Brito J (2013) Predicting survival of endoscopic gastrostomy candidates using the underlying disease, serum cholesterol, albumin and transferrin levels. Nutr Hosp 28(4): 1280-1285.

Galaski A, Peng WW, Ellis M, Darlingm P, Common A, Tucker E (2009) Gastrostomy tube placement by radiological versus endoscopic methods in an acute care setting: a retrospective review of frequency, indications, complications and outcomes. Canadian Journal of Gastroenterology \& Hepatology 23(2): 109114.

Gore T, Hunt CW, Parker FP, Raines KH (2011) The effects of simulated clinical experiences on anxiety: nursing students' perspectives. Clinical Simulation in Nursing 7(5): e175-e180.

Harder BN (2009) Evolution of simulation use in health care education. Evolution of simulation use in health care education. Clinical Simulation in Nursing 5(5): e169-e172.

Hope A, Garside J, Prescott S (2011) Rethinking theory and practice: pre-registration student nurses experiences of simulation teaching and learning in the acquisition of clinical skills in preparation for practice. Nurse Education Today 31: 711-715.

Hunter C, Ravert P (2010) Nursing students' perceptions of learning outcomes throughout simulation experiences. Undergraduate Research Journal for the Human Sciences 9: 1-4.

Jarzemsky P (2012) Advancing the science of human patient simulation in nursing education. Nursing Clinics of North America 47: 355-364.

Jefferies PR, Rizzolo MA (2006) Designing and Implementing Models for the Innovative Use of Simulation to Teach Nursing Care of Ill Adults and Children: a National, Multi-Site, Multi-Method Study. New York: National League for Nursing.

Kardong-Edgren S, Lungstrom N, Bendel R (2009) VitalSim versus SimMan: a comparison of BSN student test scores, knowledge retention, and satisfaction. Clinical Simulation in Nursing 5(3).

Kinney S, Henderson D (2008) Comparison of low fidelity simulation learning strategy with traditional lecture. Clinical Simulation in Nursing 4: e15-e18.

Liaw SY, Scherpbier A, Rethans Jan-J, Yobas PK (2012) Assessment for simulation learning outcomes: a comparison of knowledge and self-reported confidence with observed clinical performance. Nurse Education Today 32: e35-e39.

Lundberg KM (2008) Promoting self-confidence in clinical nursing students. Nurse Educator 33(2): 86-89.

Martin L, Blomberg J, Lagergren P (2012) Patients' perspectives of living with a percutaneous endoscopic gastrostomy (PEG). BMC Gastroenterology 12(126): 18.

McConville SA, Lane AM (2006) Using on-line video clips to enhance self-efficacy toward dealing with difficult situations among nursing students. Nurse Education Today 26: 200-208.

Morgan PJ, Cleave-Hogg D, McIlroy J, Devitt JH (2002) Simulation technology: a comparison of experiential and visual learning for undergraduate medical students. Anesthesiology 96: 10-16.

Murray C, Grant MJ, Howarth ML, Leigh J (2008) The use of simulation as a teaching and learning approach to support practice learning. Nurse Education in Practice 8: 5-8.

National League for Nursing (2005) Position statement: Transforming nursing education. Nursing Education Perspectives 26(3): 195-197. 
Potack JZ, Chokhavatia S (2008) Complications of and controversies associated with percutaneous endoscopic gastrostomy: report of a case and literature review. Medscape Journal of Medicine 10(6): 142.

Prion S (2008) A practical framework for evaluating the impact of clinical simulation experiences in pre licensure nursing education. Clinical Simulation in Nursing 4(5): e69-e78.

Ross JG (2012) Simulation and psychomotor skill acquisition: a review of the literature. Clinical Simulation in Nursing 8(9): e429-e435.

Salina L, Ruffinengo C, Garrino L, Massariello P, Charrier L, Martin B, Favale MS, Dimonte V (2012) Effectiveness of an educational video as an instrument to refresh and reinforce the learning of a nursing technique: a randomized controlled trial. Perspective of Medical Education 1: 67-75.

Schrag SP, Sharma R, Jaik NP, Seamon MJ, Lukaszczyk JJ, Martin ND, Hoey BA, Stawicki SP (2007) Complications related to percutaneous endoscopic gastrostomy (peg) tubes. A comprehensive clinical review. Journal of Gastrointestinal and Liver Diseases 16(4): 407-418.

Society for Simulation in Healthcare (2009) What is simulation? 2009 May 1. Ref Type: Internet Communication.

Tiffen J, Graf N, Corbridge S (2009) Effectiveness of a low-fidelity simulation experience in building confidence among advanced practice nursing graduate students. Clinical Simulation in Nursing 5(3): e113-e117.

Tun JK, Kneebone R (2011) Bridging worlds: applying the science of motor learning to clinical education. Medical Education 45: 111-114.

Vanis N, Saray A, Gornjakovic S, Mesihovic R (2012) Percutaneous endoscopic gastrostomy (PEG): Retrospective analysis of a 7-year clinical experience. Acta Inform Med 20(4): 235-237.

Williams B, French J, Brown T (2009) Can interprofessional education DVD simulations provide an alternative method for clinical placements in nursing? Nurse Education Today 29(6): 666-670.

Wood G, Haber J (2009) Nursing Research ( $7^{\text {th }}$ edn.). Mosby, Elsevier.

Zhang C, Thompson S, Miller C (2011) A review of simulation-based interprofessional education. Clinical Simulation in Nursing 7(4): e117-e126. 
